\title{
Origin of the Enhanced Binding Capability toward Axial Nitrogen Bases of Ni(II) Porphyrins Bearing Electron- Withdrawing Substituents: An Electronic Structure and Bond Energy Analysis
}

\footnotetext{
Mario Amati, ${ }^{\dagger}$ Evert Jan Baerends ${ }^{\ddagger}$, Giampaolo Ricciardi, ${ }^{*}$, Angela Rosa ${ }^{*}, \dagger$

†Università della Basilicata, Dipartimento di Scienze, Viale dell'Ateneo Lucano 10, 85100 Potenza, Italy

tVU University Amsterdam, Theoretical Chemistry, FEW, De Boelelaan 1083, 1081 HV Amsterdam, The Netherlands

${ }^{\S}$ Università della Basilicata, Scuola di Scienze Agrarie, Forestali, Alimentari e Ambientali (SAFE), Viale dell'Ateneo Lucano 10, 85100 Potenza, Italy

*Corresponding Authors

E-mail: angela.rosa@unibas.it (A.R.)

E-mail: giampaolo.ricciardi@unibas.it (G. R.)
} 
Table S1. Selected Bond Lengths ( $($ ) and Angles (deg) Calculated for NiTPP and NiTPPF 20 Are Compared to the Experimental Data

\begin{tabular}{|c|c|c|c|c|c|c|c|c|}
\hline & \multicolumn{4}{|c|}{ NiTPP } & \multicolumn{4}{|c|}{$\mathrm{NiTPPF}_{20}$} \\
\hline & $\mathrm{B} 3 \mathrm{LYP}^{a}$ & B3LYP $^{b}$ & $\mathrm{BP}^{a} 6^{a}$ & $\exp ^{c}$ & $\mathrm{~B} 3 \mathrm{LYP}^{a}$ & $\mathrm{~B} 3 \mathrm{LYP}^{b}$ & $\mathrm{BP}^{a} 6^{a}$ & $\exp ^{d}$ \\
\hline$\overline{\mathrm{Ni}-\mathrm{N}_{\mathrm{p}}}$ & 1.950 & 1.956 & 1.929 & 1.931 & 1.957 & 1.955 & 1.933 & 1.925 \\
\hline $\mathrm{N}_{\mathrm{p}}-\mathrm{C}_{\alpha}$ & 1.378 & 1.375 & 1.386 & $1.377(3)$ & 1.376 & 1.375 & 1.384 & $1.373(7)$ \\
\hline $\mathrm{C}_{\alpha}-\mathrm{C}_{\text {meso }}$ & 1.389 & 1.389 & 1.395 & $1.384(4)$ & 1.386 & 1.389 & 1.391 & $1.384(8)$ \\
\hline $\mathrm{C}_{\alpha}-\mathrm{N}_{\mathrm{p}}-\mathrm{C}_{\alpha}$ & 105.3 & 105.5 & 105.2 & 104.9 & 105.0 & 105.5 & 104.8 & $105.3(2)$ \\
\hline $\mathrm{C}_{\alpha}-\mathrm{C}_{m e s o}-\mathrm{C}_{\alpha}$ & 121.7 & 121.9 & 121.0 & 121.7 & 122.7 & 121.9 & 121.8 & $122.2(3)$ \\
\hline$\varphi^{e}$ & 4.0 & 2.7 & 3.8 & 2.9 & 1.6 & 2.7 & 6.5 & 5.6 \\
\hline$\omega^{f}$ & 24.2 & 23.8 & 33.4 & 27.3 & 20.0 & 23.8 & 28.3 & 33.5 \\
\hline$\theta^{g}$ & 71.6 & 74.8 & 69.2 & 78.7 & 84.2 & 74.8 & 72.9 & 73.8 \\
\hline
\end{tabular}

$\overline{{ }^{a} \mathrm{ADF} \text { (ZORA/TZP), average values. }{ }^{b} \text { Turbomole (def2-TZVP), average values. }{ }^{c} \text { Experimental values, }}$ from ref.1. ${ }^{d}$ Experimental values, from ref. $2 .{ }^{e} \varphi$ is the $\mathrm{C}_{\alpha}-\mathrm{N}-\mathrm{N}-\mathrm{C}_{\alpha}$ torsional angle, which provides a measure of the tilting of adjacent pyrrole ring planes (saddling). ${ }^{f} \omega$ is the $\mathrm{C}_{\alpha}-\mathrm{N}-\mathrm{N}-\mathrm{C}_{\alpha}$ torsional angle of the opposite pyrrole ring planes with respect to an axis through the nitrogen atoms (ruffling). ${ }^{g} \theta$ is the dihedral angle between the aryl mean plane and the 24-atom porphyrin mean plane. 
Table S2. Selected Bond Lengths (Å) and Angles (deg) Calculated for NiTPP(py) and $\mathrm{NiTPPF}_{20}$ (py)

\begin{tabular}{|c|c|c|c|c|c|c|}
\hline & \multicolumn{3}{|c|}{ NiTPP(py) } & \multicolumn{3}{|c|}{$\mathrm{NiTPPF}_{20}$ (py) } \\
\hline & $\mathrm{B} 3 \mathrm{LYP}^{a}$ & $\mathrm{~B} 3 \mathrm{LYP}^{b}$ & $\mathrm{BP}^{2} 6^{a}$ & ${\mathrm{~B} 3 \mathrm{LYP}^{a}}^{a}$ & $\mathrm{~B} 3 \mathrm{LYP}^{b}$ & $\mathrm{BP}^{a}{ }^{a}$ \\
\hline $\mathrm{Ni}-\mathrm{N}_{\mathrm{p}}$ & 2.052 & 2.059 & 2.047 & 2.055 & 2.060 & 2.049 \\
\hline $\mathrm{Ni}-\mathrm{N}_{\mathrm{py}}$ & 2.129 & 2.138 & 2.055 & 2.119 & 2.129 & 2.057 \\
\hline $\mathrm{C}_{\alpha}-\mathrm{C}_{\text {meso }}$ & 1.402 & 1.404 & 1.405 & 1.400 & 1.400 & 1.404 \\
\hline $\mathrm{C}_{\alpha}-\mathrm{N}_{\mathrm{p}}-\mathrm{C}_{\alpha}$ & 106.7 & 106.9 & 106.1 & 106.6 & 106.8 & 105.9 \\
\hline $\mathrm{C}_{\alpha}-\mathrm{C}_{\text {meso }}-\mathrm{C}_{\alpha}$ & 124.8 & 124.8 & 124.6 & 125.6 & 125.6 & 125.4 \\
\hline$\omega^{c}$ & 3.5 & 4.0 & 5.0 & 3.0 & 2.5 & 3.9 \\
\hline$\psi^{d}$ & 44.9 & 44.8 & 44.9 & 44.9 & 44.9 & 44.9 \\
\hline$\Delta_{24}{ }^{e}$ & 0.29 & 0.29 & 0.28 & 0.29 & 0.31 & 0.29 \\
\hline$\Delta_{4 \mathrm{~N}}^{f}$ & 0.24 & 0.24 & 0.23 & 0.24 & 0.25 & 0.25 \\
\hline
\end{tabular}

$\overline{{ }^{a} \mathrm{ADF}(\mathrm{ZORA} / \mathrm{TZP}), \text { average values. }{ }^{b} \text { Turbomole (def2-TZVP), average values. }{ }^{c} \omega}$ is the $\mathrm{C}_{\alpha}-\mathrm{N}-\mathrm{N}-\mathrm{C}_{\alpha}$ torsional angle of the opposite pyrrole ring planes with respect to an axis through the nitrogen atoms (ruffling). ${ }^{d} \psi$ is the angle between the pyridine plane and the plane through the $\mathrm{N}_{\mathrm{p}}-\mathrm{Ni}-\mathrm{N}_{\mathrm{p}}$ atoms, where $\mathrm{N}_{\mathrm{p}}$ are the nitrogen atoms of the opposite pyrroles. ${ }^{e} \Delta_{24}$ is the distance between the nickel atom and the 24atom porphyrin mean plane (doming). ${ }^{f} \Delta_{4 \mathrm{~N}}$ is the distance between the nickel atom and the four pyrrolic nitrogen atom mean plane. 
Table S3. Selected Bond Lengths ( $\AA$ ) and Angles (deg) Calculated for NiTPP $(\mathrm{py})_{2}$ and $\mathrm{NiTPPF}_{20}(\mathrm{py})_{2}$ Are Compared to the Experimental Data

\begin{tabular}{ccccccccc}
\hline & \multicolumn{3}{c}{$\mathrm{NiTP}$} & & \multicolumn{4}{c}{$\mathrm{NiTPP}_{20}(\mathrm{py})_{2}$} \\
\cline { 2 - 3 } \cline { 7 - 9 } & B3LYP $^{a}$ & B3LYP $^{b}$ & BP86 $^{a}$ & & B3LYP $^{a}$ & B3LYP $^{b}$ & BP86 $^{a}$ & exp. $^{c}$ \\
\hline $\mathrm{Ni}-\mathrm{N}_{\mathrm{p}}$ & 2.055 & 2.060 & 2.054 & & 2.058 & 2.061 & 2.054 & 2.044 \\
$\mathrm{Ni}-\mathrm{N}_{\mathrm{py}}$ & 2.288 & 2.323 & 2.217 & & 2.296 & 2.320 & 2.231 & 2.223 \\
$\mathrm{C}_{\alpha}-\mathrm{C}_{\text {meso }}$ & 1.407 & 1.407 & 1.412 & & 1.403 & 1.405 & 1.407 & $1.400(2)$ \\
$\mathrm{C}_{\alpha}-\mathrm{N}_{\mathrm{p}}-\mathrm{C}_{\alpha}$ & 107.3 & 107.5 & 106.8 & & 107.1 & 107.4 & 106.5 & $106.8(1)$ \\
$\mathrm{C}_{\alpha}-\mathrm{C}_{\text {meso }}-\mathrm{C}_{\alpha}$ & 125.2 & 125.3 & 125.0 & & 126.3 & 126.2 & 126.0 & 126.2 \\
$\varphi^{d}$ & 2.8 & 3.4 & 4.9 & & 0.0 & 0.0 & 1.8 & 1.6 \\
$\omega^{e}$ & 10.2 & 7.9 & 9.4 & & 0.0 & 0.0 & 0.1 & 2.7 \\
$\theta^{f}$ & 71.5 & 68.5 & 62.5 & & 90.0 & 90.0 & 82.7 & 70.4 \\
\hline
\end{tabular}

$\overline{{ }^{a} \mathrm{ADF}(\mathrm{ZORA} / \mathrm{TZP}) \text {, average values. }{ }^{b} \text { Turbomole (def2-TZVP), average values. }{ }^{c} \text { Experimental }}$ values, from ref. 2. ${ }^{d} \varphi$ is the $\mathrm{C}_{\alpha}-\mathrm{N}-\mathrm{N}-\mathrm{C}_{\alpha}$ torsional angle, which provides a measure of the tilting of adjacent pyrrole ring planes (saddling). ${ }^{e} \omega$ is the $\mathrm{C}_{\alpha}-\mathrm{N}-\mathrm{N}-\mathrm{C}_{\alpha}$ torsional angle of the opposite pyrrole ring planes with respect to an axis through the nitrogen atoms (ruffling). ${ }^{f} \theta$ is the dihedral angle between the aryl mean plane and the 24-atom porphyrin mean plane. 
Table S4. Hirshfeld and NBO Charges Calculated at B3LYP Level

\begin{tabular}{|c|c|c|c|c|}
\hline & \multicolumn{2}{|c|}{ NiTPP } & \multicolumn{2}{|c|}{$\mathrm{NiTPPF}_{20}$} \\
\hline & Hirshfeld & $\mathrm{NBO}$ & Hirshfeld & NBO \\
\hline $\mathrm{Ni}$ & 0.374 & 1.004 & 0.391 & 1.019 \\
\hline $\mathrm{N}_{\mathrm{p}}$ & -0.156 & -0.513 & -0.149 & -0.508 \\
\hline $\mathrm{C}_{\alpha}{ }^{a}$ & 0.0330 & 0.142 & 0.0389 & 0.154 \\
\hline $\mathrm{C}_{\mathrm{B}}^{a}$ & -0.0640 & -0.227 & -0.0570 & -0.217 \\
\hline $\mathrm{C}_{\text {meso }}$ & -0.00400 & -0.0378 & -0.0102 & -0.0346 \\
\hline $\mathrm{C}_{1}$ & 0.00680 & -0.0320 & -0.0232 & -0.144 \\
\hline $\mathrm{C}_{\mathrm{o}}{ }^{a}$ & -0.0429 & -0.197 & 0.0826 & 0.345 \\
\hline $\mathrm{C}_{\mathrm{m}}{ }^{a}$ & -0.0459 & -0.202 & 0.0637 & 0.261 \\
\hline $\mathrm{C}_{\mathrm{p}}$ & -0.0476 & -0.208 & 0.0734 & 0.286 \\
\hline $\mathrm{H}\left(\mathrm{C}_{\mathrm{o}}\right)^{a} / \mathrm{F}\left(\mathrm{C}_{\mathrm{o}}\right)^{a}$ & 0.0492 & 0.214 & -0.0683 & -0.284 \\
\hline $\mathrm{H}\left(\mathrm{C}_{\mathrm{m}}\right)^{a} / \mathrm{F}\left(\mathrm{C}_{\mathrm{m}}\right)^{a}$ & 0.0491 & 0.209 & -0.0734 & -0.275 \\
\hline $\mathrm{H}\left(\mathrm{C}_{\mathrm{p}}\right) / \mathrm{F}\left(\mathrm{C}_{\mathrm{p}}\right)$ & 0.0484 & 0.208 & -0.0678 & -0.272 \\
\hline
\end{tabular}

${ }^{a}$ Average values. 
Table S5. B3LYP/TZP Energy (eV) of the Frontier MOs of NiTPP and NiTPPF 20 Computed in the Gas-phase and in Toluene Solution (COSMO)

\begin{tabular}{|c|c|c|c|c|c|c|}
\hline \multirow[t]{2}{*}{$\overline{\mathrm{MOs}}$} & \multicolumn{3}{|c|}{ NiTPP } & \multicolumn{3}{|c|}{$\mathrm{NiTPPF}_{20}$} \\
\hline & gas phase & toluene & & gas phase & toluen & \\
\hline $3 d_{x^{2}-y^{2}}^{*}$ & -1.45 & -1.61 & -0.16 & -2.37 & -2.22 & 0.15 \\
\hline "e $\mathrm{e}_{\mathrm{g}} * ”$ & -2.34 & -2.46 & -0.12 & -3.25 & -3.09 & 0.16 \\
\hline$" a_{2 u} "$ & -5.32 & -5.44 & -0.12 & -6.39 & -6.24 & 0.15 \\
\hline " $a_{1 u} "$ & -5.39 & -5.52 & -0.13 & -6.23 & -6.07 & 0.16 \\
\hline $3 d_{\pi}$ & -6.13 & -6.28 & -0.15 & -7.00 & -6.84 & 0.16 \\
\hline $3 d_{z^{2}}$ & -6.30 & -6.47 & -0.17 & -7.14 & -7.00 & 0.14 \\
\hline
\end{tabular}

Table S6. B3LYP/TZP Energy (eV) of the Frontier MOs of Pyridine Computed in the Gas-phase and in Toluene Solution (COSMO)

\begin{tabular}{lccc}
\hline MOs & gas phase & toluene & \\
\hline $3 \mathrm{~b}_{2}($ LUMO) & -1.02 & -1.02 & 0.00 \\
$11 \mathrm{a}_{1}($ HOMO $)$ & -7.16 & -7.31 & -0.15 \\
$1 \mathrm{a}_{2}($ HOMO- $)$ & -7.38 & -7.36 & 0.02 \\
\hline
\end{tabular}


Table S7. B3LYP/TZP Energy Decomposition Analysis of the Formation Energy, $\Delta E_{1}(\mathrm{~kJ} / \mathrm{mol})$, of NiTTP(py) and $\mathrm{NiTPPF}_{20}$ (py) from the Nickel(II) Porphyrin and Pyridine Fragments in the Gas-phase and in Toluene Solution (COSMO Model)

\begin{tabular}{|c|c|c|c|c|}
\hline & \multicolumn{2}{|c|}{ NiTPP(py) } & \multicolumn{2}{|c|}{$\mathrm{NiTPPF}_{20}(\mathrm{py})$} \\
\hline & toluene & gas phase $^{a}$ & toluene & gas phase $^{a}$ \\
\hline$\Delta E_{\mathrm{geo}}$ & 49.3 & 49.3 & 52.2 & 52.2 \\
\hline$\Delta E_{\text {excit }}$ & 12.6 & 12.6 & 5.8 & 5.8 \\
\hline$\Delta E_{\text {prep }}\left(\Delta E_{\text {geo }}+\Delta E_{\text {excit }}\right)$ & 61.9 & 61.9 & 58.0 & 58.0 \\
\hline$\Delta E_{\text {Pauli }}$ & 267.9 & 267.9 & 270.4 & 270.4 \\
\hline$\Delta V_{\text {elstat }}$ & -242.9 & -243.3 & -254.4 & -255.4 \\
\hline$\Delta E^{0}\left(\Delta E_{\text {Pauli }}+\Delta V_{\text {elstat }}\right)$ & 25.0 & 24.6 & 16.0 & 15.0 \\
\hline$\Delta E_{\mathrm{A}_{1}}$ & -75.5 & -76.7 & -81.8 & -83.2 \\
\hline$\Delta E_{\mathrm{A}_{2}}$ & -2.7 & -3.0 & -2.6 & -3.4 \\
\hline$\Delta E_{\mathrm{B}_{1}}$ & -7.0 & -7.4 & -7.5 & -8.4 \\
\hline$\Delta E_{\mathrm{B}_{2}}$ & -8.9 & -10.0 & -10.3 & -11.2 \\
\hline$\Delta E_{\mathrm{oi}}\left(\Sigma_{\Gamma} \Delta E_{\Gamma}\right)$ & -94.1 & -97.1 & -102.2 & -106.2 \\
\hline$\overline{\Delta E_{\text {int }}\left(\Delta E^{0}+\Delta E_{\mathrm{oi}}\right)}$ & -69.1 & -72.5 & -86.2 & -91.2 \\
\hline \multicolumn{5}{|l|}{$\overline{\text { Solvation Energy }}$} \\
\hline Fragments & -19.2 & - & -40.6 & - \\
\hline Adduct & -17.6 & - & -35.6 & - \\
\hline$\overline{\Delta E_{\mathrm{SOLV}}}$ & 1.6 & - & 5.0 & - \\
\hline$\Delta E_{1}\left(\Delta E_{\text {prep }}+\Delta E_{\text {int }}+\Delta E_{\text {SOLV }}\right)$ & -5.6 & -10.6 & -23.2 & -33.2 \\
\hline
\end{tabular}

${ }^{a}$ Data taken from Table 6 , this work. 


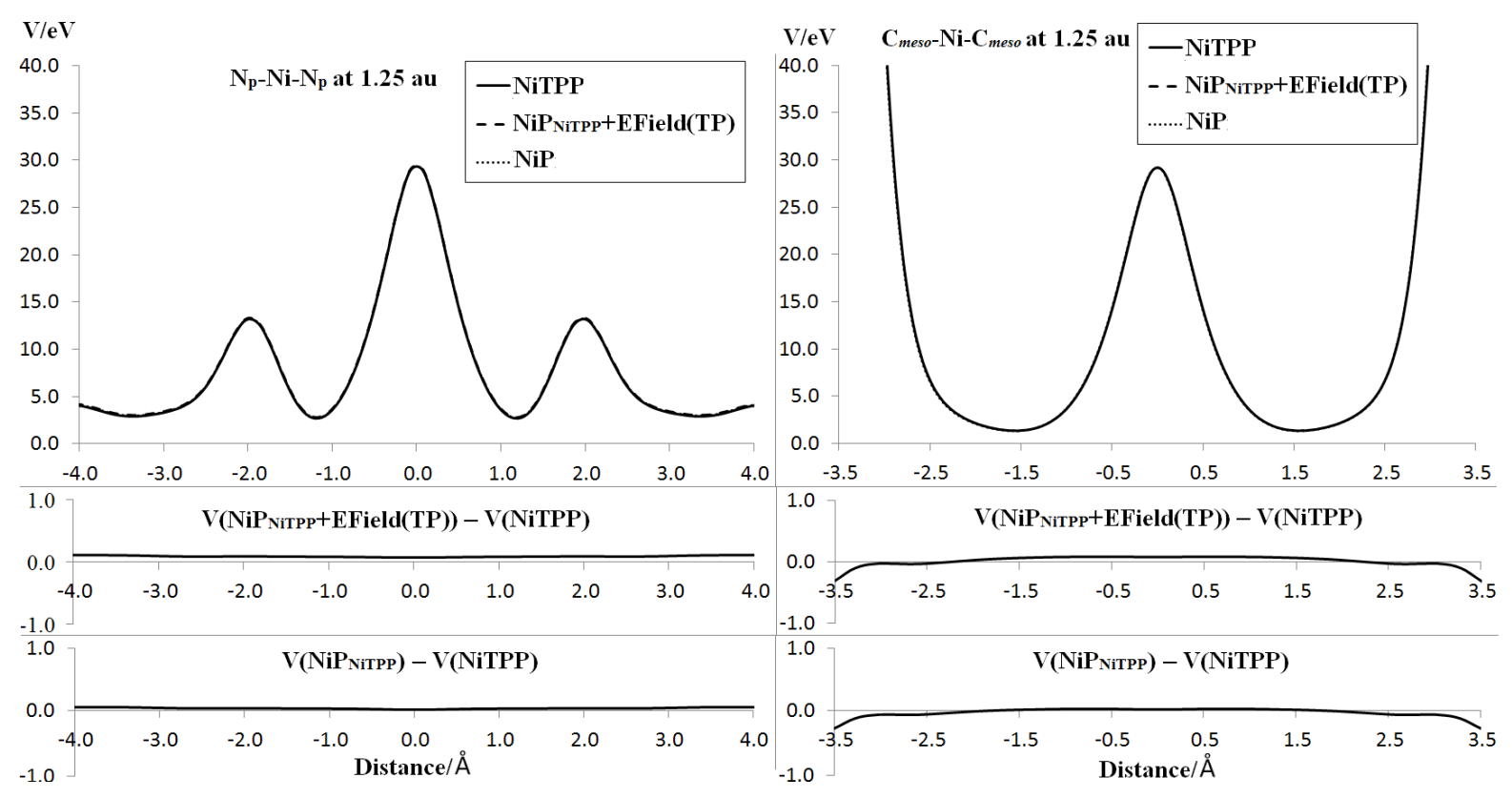

Figure S1. Electrostatic potential (SCF potential, eV) computed at 1.25 au $(0.661 \AA)$ above the macrocycle mean plane in NiTPP (full SCF computation), $\mathrm{NiP}_{\mathrm{NiTPP}}$ and $\mathrm{NiP}_{\text {NiTPP }}+$ EField(TP). The potential is plotted along two axes: $\mathrm{N}_{\mathrm{p}}-\mathrm{Ni}-\mathrm{N}_{\mathrm{p}}$ (left) and $\mathrm{C}_{\text {meso }}-\mathrm{Ni}-\mathrm{C}_{\text {meso }}$ (right). The deviation of the $\mathrm{NiP}_{\text {NiTPP }}+$ EField(TP) and $\mathrm{NiP}_{\mathrm{NiTPP}}$ potentials from the NiTPP full potential is sketched below each graph. 


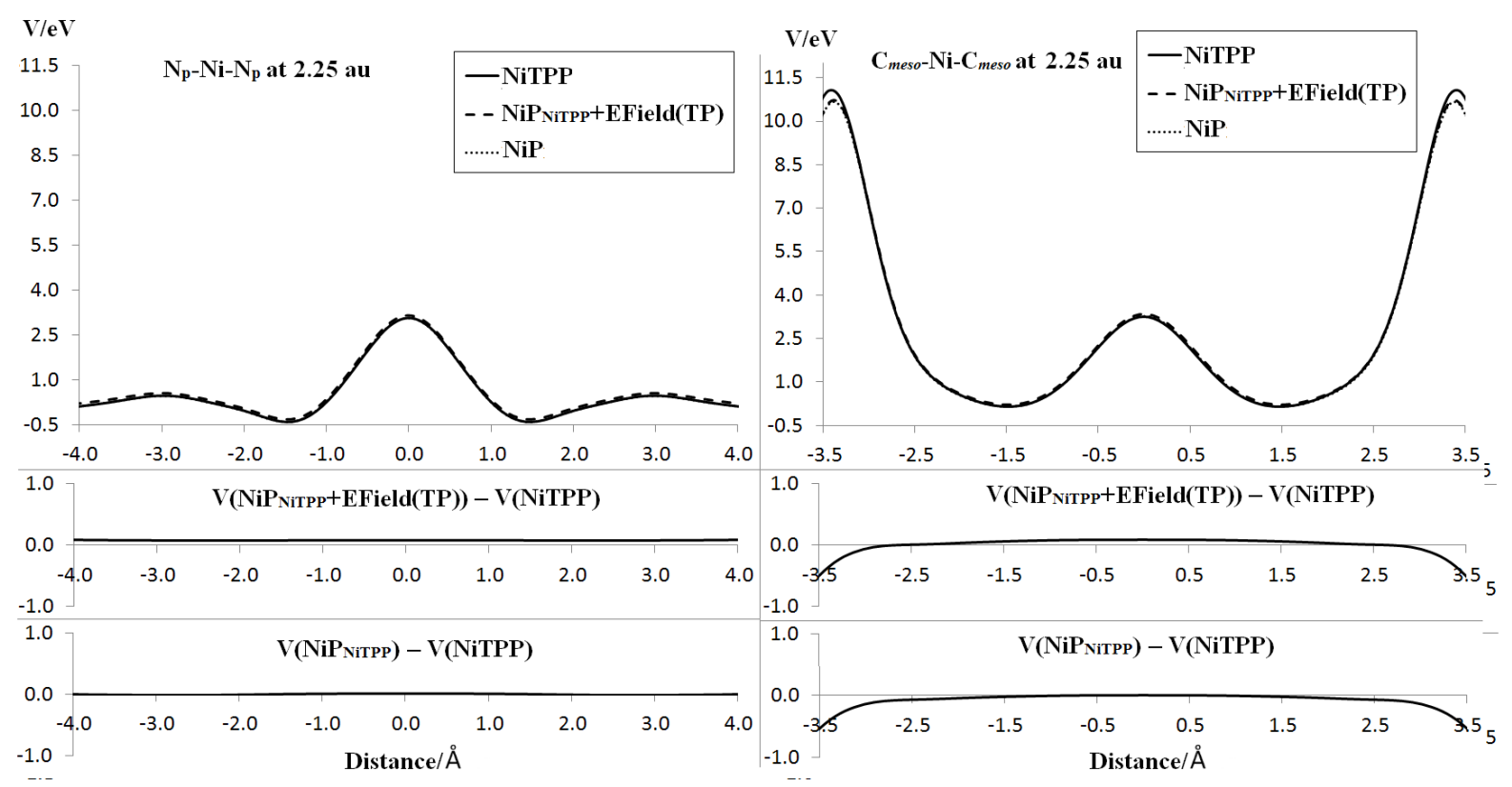

Figure S2. Electrostatic potential (SCF potential, eV) computed at 2.25 au (1.191 $\AA$ ) above the macrocycle mean plane in NiTPP (full SCF computation), $\mathrm{NiP}_{\mathrm{NiTPP}}$ and $\mathrm{NiP}_{\mathrm{NiTPP}}+\mathrm{EField}(\mathrm{TP}$ ). The potential is plotted along two axes: $\mathrm{N}_{\mathrm{p}}-\mathrm{Ni}-\mathrm{N}_{\mathrm{p}}$ (left) and $\mathrm{C}_{\text {meso }}-\mathrm{Ni}-\mathrm{C}_{\text {meso }}$ (right). The deviation of the $\mathrm{NiP}_{\mathrm{NiTP}}+\mathrm{EField}(\mathrm{TP})$ and $\mathrm{NiP}_{\mathrm{NiTPP}}$ potentials from the NiTPP full potential is sketched below each graph. 


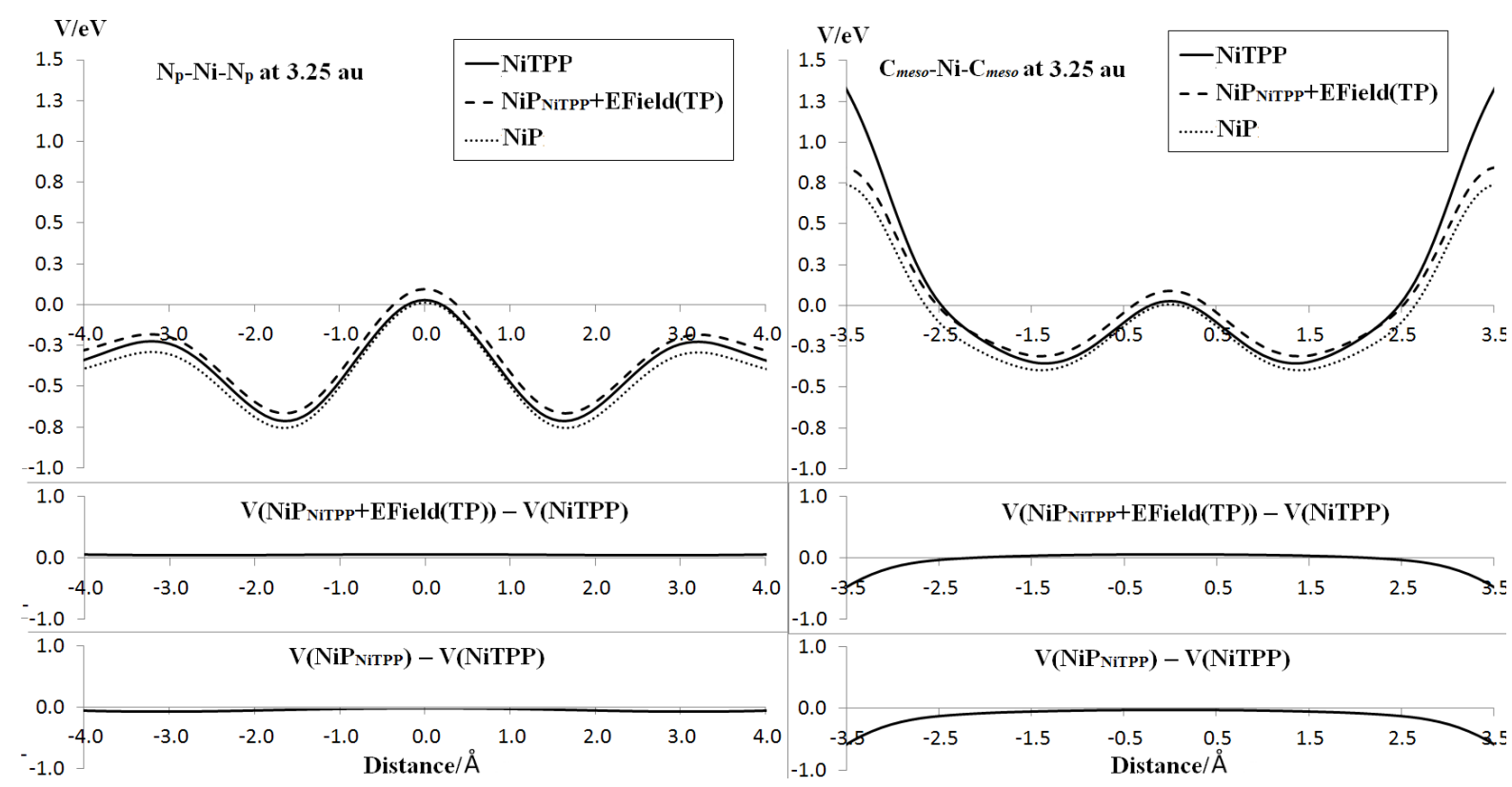

Figure S3. Electrostatic potential (SCF potential, eV) computed at 3.25 au (1.720 $\AA$ ) above the macrocycle mean plane in NiTPP (full SCF computation), $\mathrm{NiP}_{\mathrm{NiTPP}}$ and $\mathrm{NiP}_{\mathrm{NiTPP}}+\mathrm{EField}(\mathrm{TP}$ ). The potential is plotted along two axes: $\mathrm{N}_{\mathrm{p}}-\mathrm{Ni}-\mathrm{N}_{\mathrm{p}}$ (left) and $\mathrm{C}_{\text {meso }}-\mathrm{Ni}-\mathrm{C}_{\text {meso }}$ (right). The deviation of the $\mathrm{NiP}_{\text {NiTPP }}+$ EField(TP) and $\mathrm{NiP}_{\text {NiTPP }}$ potentials from the NiTPP full potential is sketched below each graph. 


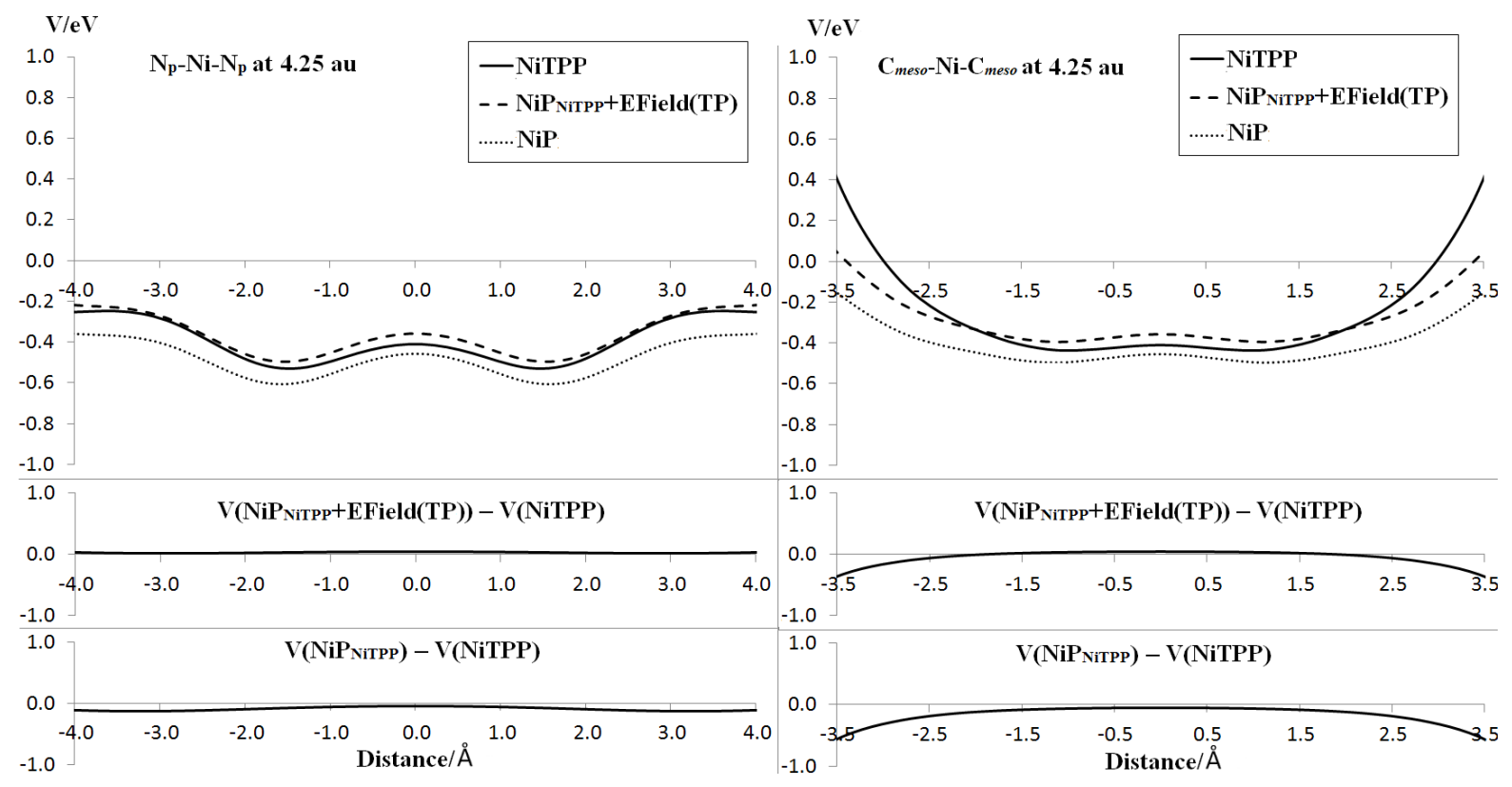

Figure S4. Electrostatic potential (SCF potential, eV) computed at 4.25 au $(2.249 \AA)$ above the macrocycle mean plane in NiTPP (full SCF computation), $\mathrm{NiP}_{\text {NiTPP }}$ and $\mathrm{NiP}_{\text {NiTPP }}+$ EField(TP). The potential is plotted along two axes: $\mathrm{N}_{\mathrm{p}}-\mathrm{Ni}-\mathrm{N}_{\mathrm{p}}$ (left) and $\mathrm{C}_{\text {meso }}-\mathrm{Ni}-\mathrm{C}_{\text {meso }}$ (right). The deviation of the $\mathrm{NiP}_{\mathrm{NiTPP}}+\mathrm{EField}(\mathrm{TP})$ and $\mathrm{NiP}_{\mathrm{NiTP}}$ potentials from the NiTPP full potential is sketched below each graph. 


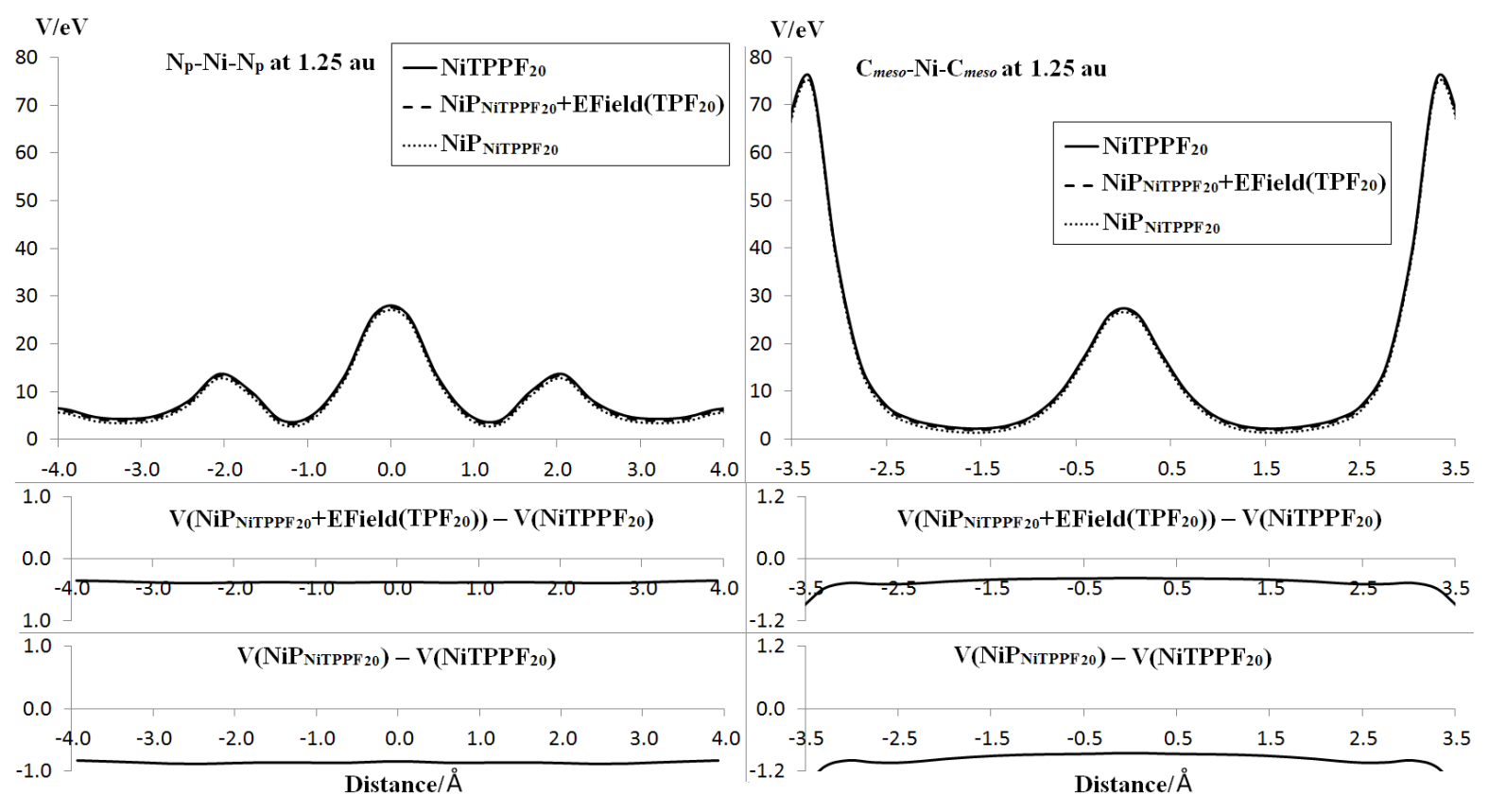

Figure S5. Electrostatic potential (SCF potential, eV) computed at 1.25 au $(0.661 \AA)$ above the macrocycle mean plane in $\mathrm{NiTPPF}_{20}$ (full $\mathrm{SCF}$ computation), $\mathrm{NiP}_{\mathrm{NiTPPF}_{20}}$ and $\mathrm{NiP}_{\mathrm{NiTPPF}_{20}}+\mathrm{EField}\left(\mathrm{TPF}_{20}\right)$. The potential is plotted along two axes: $\mathrm{N}_{\mathrm{p}}-\mathrm{Ni}-\mathrm{N}_{\mathrm{p}}$ (left) and $\mathrm{C}_{\text {meso }}-\mathrm{Ni}-\mathrm{C}_{\text {meso }}$ (right). The deviation of the $\mathrm{NiP}_{\mathrm{NiTPPF}_{20}}+\mathrm{EField}\left(\mathrm{TPF}_{20}\right)$ and $\mathrm{NiP}_{\mathrm{NiTPPF}_{20}}$ potentials from the $\mathrm{NiTPPF}_{20}$ full potential is sketched below each graph. 


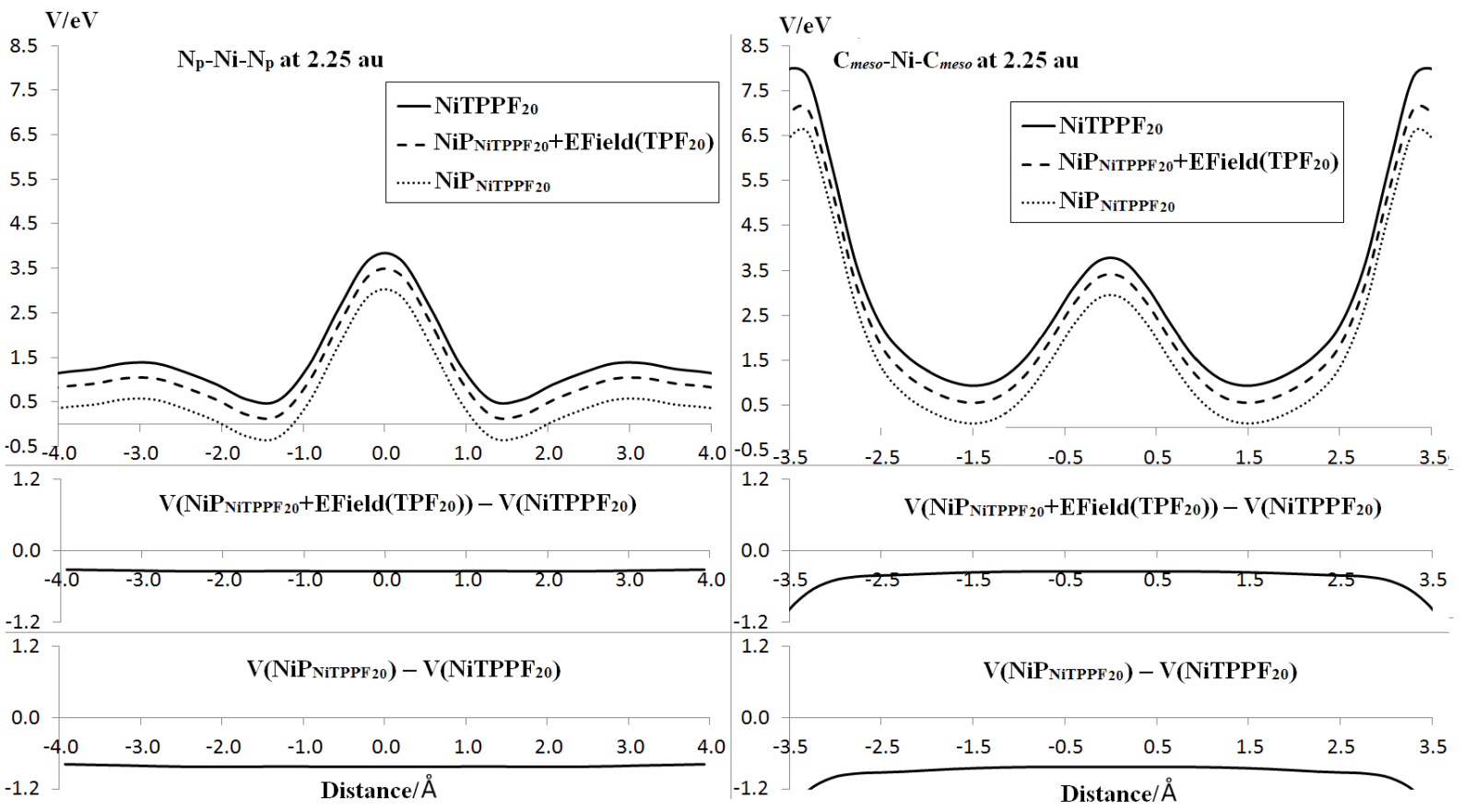

Figure S6. Electrostatic potential (SCF potential, eV) computed at 2.25 au (1.191 $\AA$ ) above the macrocycle mean plane in $\mathrm{NiTPPF}_{20}$ (full SCF computation), $\mathrm{NiP}_{\mathrm{NiTPPF} 20}$ and $\mathrm{NiP}_{\mathrm{NiTPPF}_{20}}+\mathrm{EField}\left(\mathrm{TPF}_{20}\right)$. The potential is plotted along two axes: $\mathrm{N}_{\mathrm{p}}-\mathrm{Ni}-\mathrm{N}_{\mathrm{p}}$ (left) and $\mathrm{C}_{\text {meso }}-\mathrm{Ni}-\mathrm{C}_{\text {meso }}$ (right). The deviation of the $\mathrm{NiP}_{\mathrm{NiTPPF}_{20}}+\mathrm{EField}\left(\mathrm{TPF}_{20}\right)$ and $\mathrm{NiP}_{\mathrm{NiTPPF}_{20}}$ potentials from the $\mathrm{NiTPPF}_{20}$ full potential is sketched below each graph. 


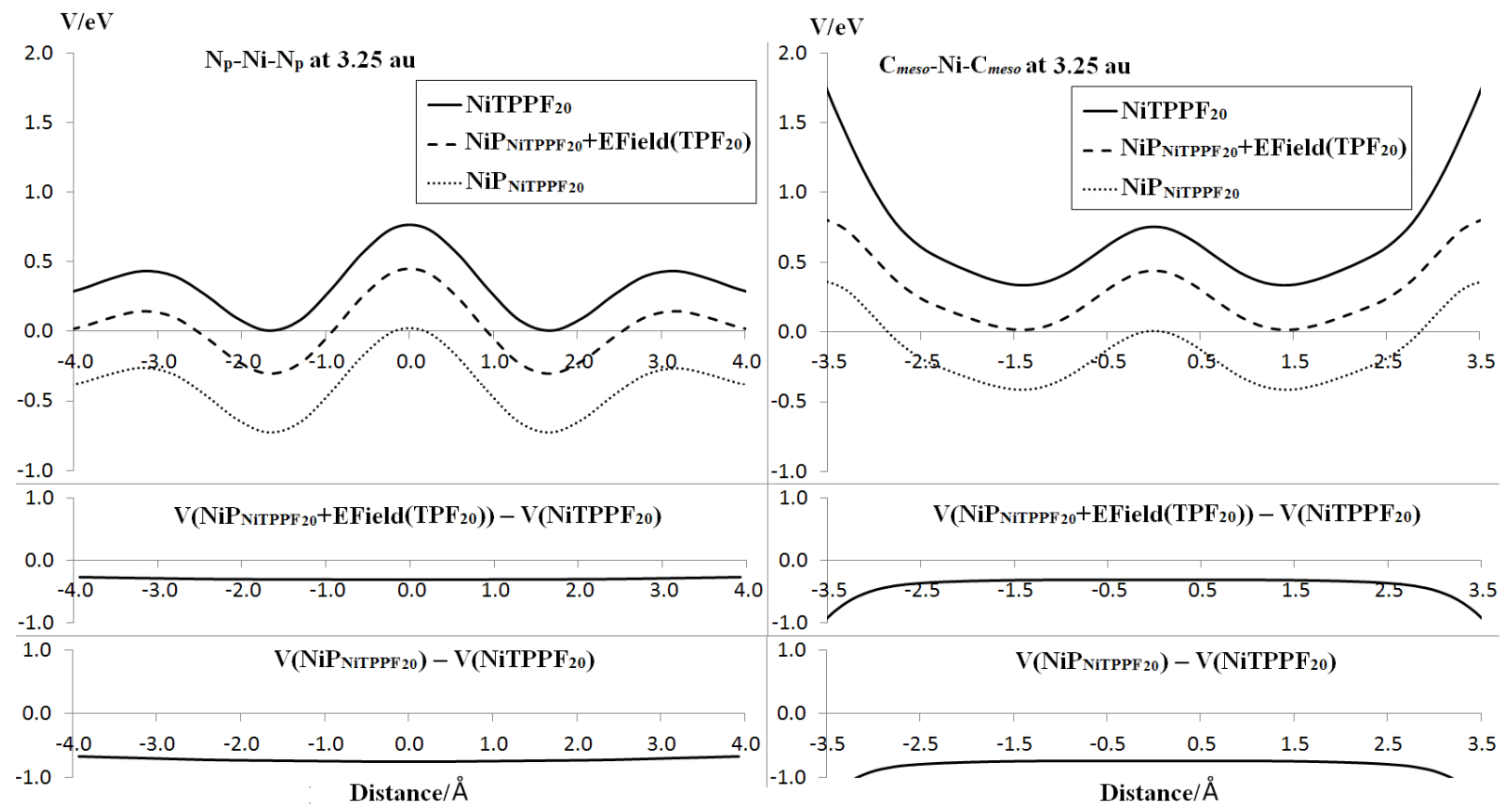

Figure S7. Electrostatic potential (SCF potential, eV) computed at 3.25 au (1.720 A) above the macrocycle mean plane in $\mathrm{NiTPPF}_{20}$ (full SCF computation), $\mathrm{NiP}_{\mathrm{NiTPPF} 20}$ and $\mathrm{NiP}_{\mathrm{NiTPPF} 20}+\mathrm{EField}\left(\mathrm{TPF}_{20}\right)$. The potential is plotted along two axes: $\mathrm{N}_{\mathrm{p}}-\mathrm{Ni}-\mathrm{N}_{\mathrm{p}}$ (left) and $\mathrm{C}_{\text {meso }}-\mathrm{Ni}-\mathrm{C}_{\text {meso }}$ (right). The deviation of the $\mathrm{NiP}_{\mathrm{NiTPPF}_{20}}+\mathrm{EField}\left(\mathrm{TPF}_{20}\right)$ and $\mathrm{NiP}_{\mathrm{NiTPF}_{20}}$ potentials from the $\mathrm{NiTPPF}_{20}$ full potential is sketched below each graph. 


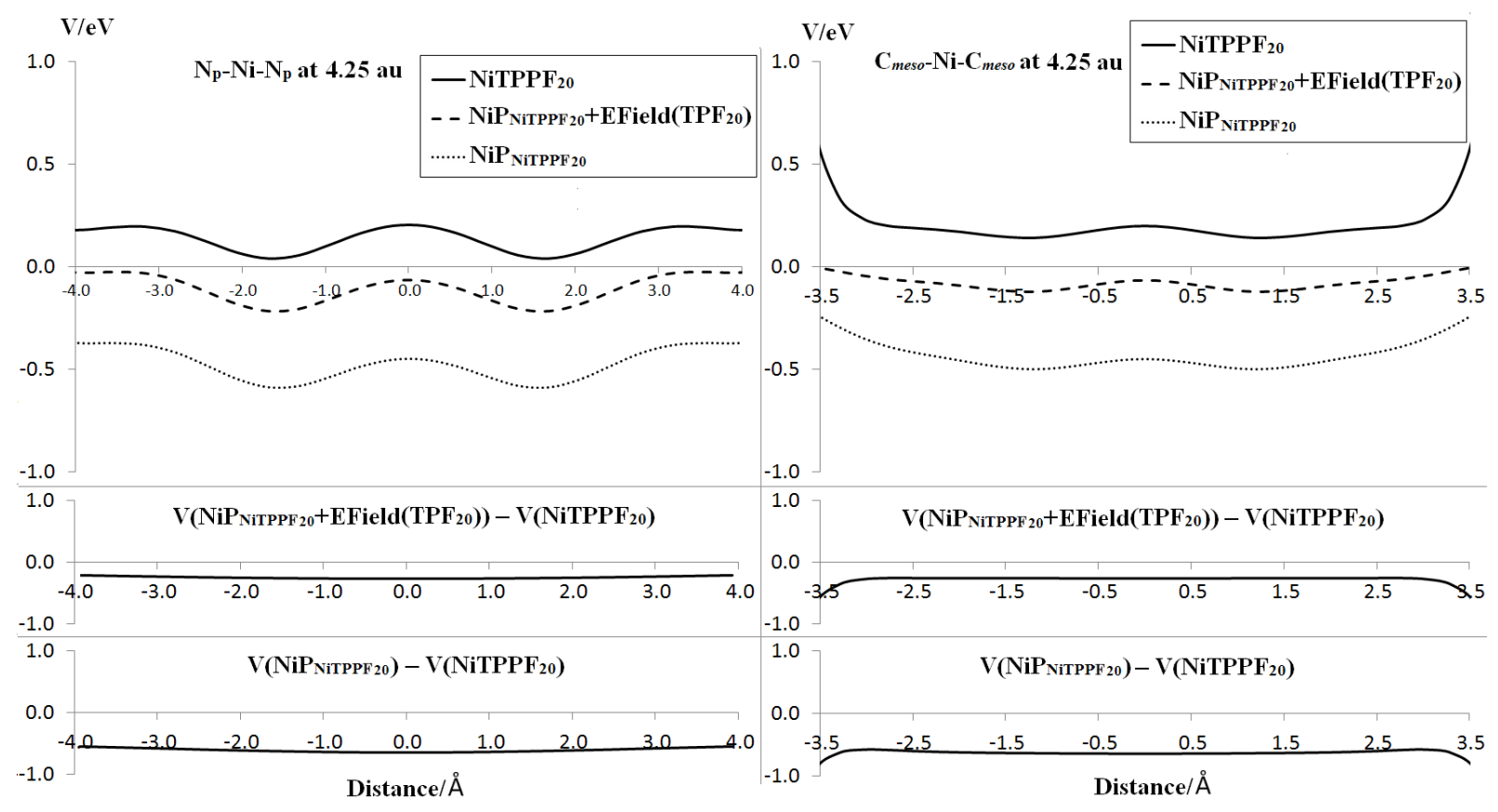

Figure S8. Electrostatic potential (SCF potential, eV) computed at 4.25 au $(2.249 \AA)$ above the macrocycle mean plane in $\mathrm{NiTPPF}_{20}$ (full $\mathrm{SCF}$ computation), $\mathrm{NiP}_{\mathrm{NiTPPF} 20}$ and $\mathrm{NiP}_{\mathrm{NiTPPF} 20}+\mathrm{EField}\left(\mathrm{TPF}_{20}\right)$. The potential is plotted along two axes: $\mathrm{N}_{\mathrm{p}}-\mathrm{Ni}-\mathrm{N}_{\mathrm{p}}$ (left) and $\mathrm{C}_{\text {meso }}-\mathrm{Ni}-\mathrm{C}_{\text {meso }}$ (right). The deviation of the $\mathrm{NiP}_{\mathrm{NiTPP}_{20}}+\mathrm{EField}\left(\mathrm{TPF}_{20}\right)$ and $\mathrm{NiP}_{\mathrm{NiTPPF}_{20}}$ potentials from the $\mathrm{NiTPPF}_{20}$ full potential is sketched below each graph.

\section{References}

1. Maclean, A.; Foran, G.; Kennedy, B.; Turner, P.; Hambley, T. Structural Characterization of Nickel(II) Tetraphenylporphyrin. Aust. J. Chem. 1996, 49, 1273-1278.

2. Dommaschk, M.; Thoms, V.; Schütt, C.; Näther, C.; Puttreddy, R.; Rissanen, K.; Herges, R. Coordination-Induced Spin-State Switching with Nickel Chlorin and Nickel Isobacteriochlorin. Inorg. Chem. 2015, 54, 9390-9392. 